\title{
Challenges of running a GMP facility for regenerative medicine in a public hospital
}

\author{
Mariele Viganò ${ }^{1}$, Rosaria Giordano*,1 \& Lorenza Lazzari ${ }^{1}$ \\ ${ }^{1}$ Cell Factory, Laboratory of Regenerative Medicine, Department of Services \& Preventive Medicine, Fondazione IRCCS Ca' Granda \\ Ospedale Maggiore Policlinico, 20122 Milano, Italy \\ * Author for correspondence: Tel.: +39 025503 4057; Fax +39 025503 2796; rosaria.giordano@policlinico.mi.it
}

\begin{abstract}
Advanced therapy medicinal products represent a new generation of medicinal products for regenerative medicine. Since the implementation of the EU regulation for this innovative class of drugs, the academic and hospital institutions have played a central role in their development and manufacture. For these institutions that are not familiar with the industrial context, being in compliance with the pharmaceutical standards is extremely challenging. This report describes how we dealt with some specific issues during our hospital-based GMP experience. Furthermore, we identify as a future perspective the consistent stimulating contribution that a public entity can ensure for advanced therapy medicinal product development and licensing.
\end{abstract}

First draft submitted: 10 April 2017; Accepted for publication: 21 August 2017; Published online: 8 November 2017

Keywords: advanced therapy medicinal products $\bullet$ cell therapy $\bullet$ GMP $\bullet$ investigational medicinal products $\bullet$ regenerative medicine $\bullet$ stem cells

Regenerative medicine is an innovative and fast-moving field in which cell therapy is applied to restore the function of cells, tissues and organs. With the entry into enforcement of the specific EU regulation (EC) no. 1394/2007, human cells, tissues, and cellular and tissue-based products obtained after substantial manipulation or not intended to be used for the same essential function in the recipient as in the donor, have been classified as pharmaceutical products under the heading of 'Advanced Therapy Medicinal Products' (ATMP) [1]. These products in Europe are regulated by the general rules of medicinal products and therefore are governed, by the same specific legislation as industrially produced drugs, with the sole exclusion of the products falling under the so-called 'hospital exemption' (article 28 of EC no. 1394/2007) that are issued on a national specific basis [2,3]. In enforcement of the European regulation 1394/2007, all ATMP must be prepared according to GMP and be in compliance with investigational medicinal product or marketing authorization requirements and postmarketing pharmacovigilance rules. In this context, cell and tissue-derived drugs (as for any other medicinal product) must be produced in authorized manufacturing centers that, in compliance with pharmaceutical quality standards, are able to ensure an adequate level of microbiological safety to obtain cell products available for human use [4].

The aims of this article are as follows: first, to briefly summarize the basic requirements of GMP that may represent obstacles to the implementation of a cell-manufacturing unit in a hospital environment and to give information on how we overcame these obstacles, and second, to give our perspective on the role of academic entities in the development of ATMP.

\section{Our history \& authorization}

Our facility is located at the 'Ospedale Maggiore' of Milan, which is traditionally known as 'Ca' Granda', one of the most ancient hospitals in Italy, and was founded by the Duke Francesco Sforza in 1456. Starting from its origin, the hospital was always economically supported by legacies, donations and citizens' contributions.

In 1998, our group started as a branch of the Milano Cord Blood Bank only at a research and development level, and in 2000, thanks to a generous donation, the project to develop a GMP facility for ATMP production was launched. 
In 2007, our facility was certified by the Italian Drug Agency (Agenzia Italiana del Farmaco) in compliance with European GMP regulations (authorization number 120/2007 on 5 July 2007). The following authorizations have been obtained after successful inspections, including the last one (authorization number 166/2016 on 11 October 2016). The mission of our facility is to develop innovative ATMP for the cure of still unmet clinical needs, to promote and support Phase I-III clinical trials with ATMP, and to improve the knowledge on the biological mechanism of action of these novel medicinal products. Besides, we also provide cell products following article 28 of EC no. 1394/2007 under the last national legal obligations laid out by the Decree of the Italian Ministry of Health of 16 January 2015. This activity concerns ATMP prepared on a nonroutine basis according to specific quality standards and used within Italy in a hospital under the exclusive professional responsibility of a medical practitioner and complying with an individual medical prescription for an individual patient. Manufacture of these products is authorized by our national competent authority to ensure traceability and pharmacovigilance requirements as well as the specific quality standards equivalent to those provided in respect of the other licensed ATMP. The use of this kind of ATMP in Italy also requires a central authorization by the national competent authority (Agenzia Italiana del Farmaco). Moreover, it is not possible to use ATMP authorized under hospital exemption for clinical experimental use. Despite the absence of any publicly available database on the application of hospital exemption in Europe, our impression and personal experience is that this activity is still marginal and its effect is negligible [3].

Our core business is now represented by ATMP production for clinical trials, and in this context, we collaborate with clinical units inside the Fondazione IRCCS Ca' Granda Ospedale Maggiore Policlinico of Milano and with many other national and international partners to carry out our work. After 10 years of GMP activity, our center can claim to have multidisciplinary experience in the field of regenerative medicine [5-12].

\section{Dealing with GMP application to ATMP manufacturing in a hospital: specific hurdles \& possible solutions}

GMP rules and requirements have been classically developed for 'conventional' medicinal products; therefore, their application to ATMP and to cell and tissue manipulation requires adaptation. On the other side, the industrial approach to drug manufacturing and control and in general to the management of a pharmaceutical plant may generate several practical difficulties in a hospital environment. In this section, we will briefly summarize the main obstacles we met during our GMP experience and the solutions we applied. Please consider the following as a nonexhaustive list of the hurdles toward GMP development of ATMP. Our aim was to give an overview of those obstacles derived both from working in a hospital environment and from the biological specificities of ATMP. Cells and tissues may indeed give rise to a very special kind of drugs whose peculiarities have recently prompted the proposal by EMA of specific guidelines [13]. After a first round of consultation in 2015 and a second round in 2016, the EMA Committee for Advanced Therapy has recently endorsed the new guidelines [14], and the EC is expected to publish them soon [15].

\section{Quality assurance}

The so-called 'pharmaceutical quality system', the title to the first chapter of the GMP guidelines, ensures that "the manufacturing process is intended to guarantee the quality of the product" [4]. However, the quality system in a hospital setting is generally intended to ensure the best performance of care services to patients and not to obtain a medicinal product with predefined quality characteristics. Therefore, there should be a 'change of mind' in the quality assurance staff of a hospital involved in ATMP manufacturing. In our experience, specific training programs and the close cooperation of the cell-manufacturing unit staff with the hospital unit dedicated to quality assurance have been extremely effective in correctly driving the change. For example, the periodic autoinspection programs are conducted and planned in the context of the global planning of internal quality system visits of the hospital by people specifically trained to GMP rules. Moreover, any modification of the general procedures of the hospital that may arise from GMP rules and may involve other services of the hospital is agreed upon and authorized in written. These agreements are made and signed by the qualified person (QP) of the cell-manufacturing unit and the person responsible for that specific service inside the hospital. It is important to emphasize that strong endorsement of the hospital senior management is the key to success in this strategy.

\section{Personnel}

According to the chapter 2 of the GMP, the staff should be trained and there should be an adequate number of them. There should be clear allocation of responsibilities, and the persons responsible for production, quality control and 
the QP should be appointed by senior management. In the academic context, the cell-manufacturing units are typically created from laboratories involved in clinical-grade cell manipulation for transplantation procedures; thus, it has been not easy at all to find people with pharmaceutical training. Also, it has been hard to find correspondence inside the hospital organizational chart for very specific roles such as the QP responsible for quality control. Details on the staff performance qualification program are also discussed in the paragraph dedicated to "the human resources challenge".

\section{Premises \& equipment}

Generally, ATMP are medicinal products that cannot be terminally sterilized and therefore fall under the prescriptions of Annex I to GMP rules. This kind of products should be manufactured in a class A-GMP area (e.g., biosafety cabinet) with a class B-GMP surrounding environment. There should be evidence that the classification of the production areas is maintained during the manufacturing period; consequently, a continuous monitoring system to control the number of viable and nonviable particles is mandatory. In the public consultation launched in 2015 by EMA on the proposed guideline for GMP applied to ATMP, several stakeholders supported the possibility to accept the use of a C- or D-GMP background for cell manipulation at least for investigational medicinal products in the early phases of clinical trials. This issue may be particularly important for academic institutions that are already involved in minimal cell manipulation.

Although it may be easier and cheaper to use class C- or D-premises already available for transplantation procedures, we are strongly convinced that the potential detrimental effects on the microbiological safety of ATMP should be considered with high priority. In our experience, it has never been an issue to deal with a lower air cleanliness level in the manufacturing area, because we started with a brand new facility, and we conceived its design from the beginning as fully GMP compliant [16].

We think that only in certain cell manipulation phases, when closed or semiclosed systems and bioreactors are available, the reduction of air cleanliness level in an ATMP manufacturing area can be allowed, given that any detrimental effect on the sterility of the final product has been excluded during process validation.

Regarding premises and equipment maintenance in general, the hospital management of healthcare technology is often insufficient to completely cover all of the GMP requirements such as installation, operation and maintenance qualification and specific controls of the equipment that require specialized technicians. For that reason, additional services are agreed upon in contracts with the general services of the hospital and/or, where needed, with external companies specialized in such GMP activities ('outsourced activities').

\section{Documentation}

Considerable resources have been dedicated to establish, control, monitor and record all of the activities that directly or indirectly may affect the quality of ATMP. Suitable controls have been implemented to ensure the accuracy, integrity, availability and legibility of documents throughout the retention period. The main obstacle in this regard has been represented by the need to integrate our system with the information technology system of the hospital, which sometimes does not comply with GMP requirements. For that reason, we have implemented, according to a risk-based approach, some additional measures to protect our data by duplication and backup, having in mind that a critical issue is nowadays the integrity of data generated by computerized systems according to Annex 11 of the GMP rules.

\section{Production process \& quality control}

ATMP manufacturing, by its nature (biological variability, not stable products, short shelf life, only partly known pharmacodynamics, hardly traceable and variable pharmacokinetic), poses several challenges that always require control strategies based on a risk assessment that have to be reviewed and improved regularly. The comments made by different stakeholders to the recent EMA document [17] generally recognize these specificities, at least in the early experimental clinical phase (e.g., Phase I and II clinical trials). Several adaptations are required for the selection and validation of raw materials to allow reprocessing, especially in the case that the treatment of patients requires readministration of an autologous product, and on the need for and the extent of cleaning validation between the manufacturing of different batches from different patients. Also, in the case of noncompendial analytical methods, the extent of validation studies for quality controls should commensurate the stage of development of ATMP. Regarding all of these issues and many others related to ATMP production and quality controls, risk assessment has always driven our choices, and we were able to propose specific solutions to support our decisions. It has been 


\begin{tabular}{|c|c|}
\hline GMP classification & Function \\
\hline NC & Material reception \\
\hline NC & Material storage \\
\hline D & Material preparation \\
\hline B & Pass boxes for materials to be introduced in or taken from the manufacturing area \\
\hline NC & Personnel access to gowning room \\
\hline D, C and B & Personnel changing rooms and transit \\
\hline B & Air lock - personnel access to the manufacturing area \\
\hline B & Manufacturing areas \\
\hline A & Biosafety cabinets inside the class B-manufacturing areas \\
\hline B, C and D & Personnel exit from the manufacturing areas \\
\hline
\end{tabular}

always important in our experience to carefully explain the rational of our decisions in the clinical trial authorization dossier and in any communication with the regulatory agency.

\section{How to build \& maintain a cell-manufacturing GMP plant in a public environment}

Annex 1 of current GMP guidelines specifically dedicated to GMP standards for Sterile Medicinal Products [18] requires that the manufacture of these products occurs in controlled environments. Compliance to Annex 1 involves a strict qualifying and validation system that drives all the facility's 'life-stages' from user requirements, design and construction, until its activation, subsequent management and maintenance.

Clearly, the construction of a plant in accordance with these requirements claimed several financial engagements, both for the high investment of the first launch, and in terms of operating costs and maintenance. The economic support to these new activities, in our experience, has been granted by the availability of the generous contribution of charities to the public investment. In this context, it is therefore important to avoid errors in defining the extent and the equipment of the plant since the early stages of the project. Overestimation is obviously detrimental for unjustified constructive, operational burden and the waste of resources. On the other hand, underestimating the size and resources to be dedicated to the GMP facility may led to additional costs in the future for structural adjustment due to evolving user requirements in time. Also, the need for revalidation and approval of the changes by the competent authority with a consequent long period of inactivity should be considered. In other words, it is recommended to have a realistic picture of the manufacturing needs and to design a GMP facility with the goal to maximize efficiency and minimize product mix-up. Special attention should be given to the desired characteristics of the final product, the production process, the scale of manufacturing, the equipment to be installed in the available space and the material and personnel flow. Moreover, at this stage, it is important to consider the most efficient layout to keep the premises under control from the microbiological perspective. For example, it is useful to preliminarily draft the layout of the facility while considering the process to minimize the microbiological risks and to optimize the environmental control. A map of the microbiological- and particle-monitoring points based on a specific risk assessment should be available from the beginning. The layout of our facility has been already described [16]. Briefly, it is composed of two separated areas, the production site and the quality control laboratories. The production division occupies an area of approximately $78 \mathrm{~m}^{2}$ and includes two class-B rooms with class-A biosafety cabinets for the manipulation, a material storage area (not classified) and an area (class D) dedicated to the preparation and packaging of materials. The access to the production premises takes place through a transit corridor and different dressing rooms in increasing classes of air cleanliness from D to B. Materials are introduced in a class-B environment through class B-ventilated pass boxes. A list of rooms and respective functions are shown in Table 1.

The quality control laboratories are allocated in a separate area and include all of the equipment for quality control testing. Ancillary areas (storage room, archives and offices) complete the plant.

The design was studied to allow the manufacturing of products for different clinical trials at the same time. In addition, our facility is a good 'springboard' to launch authorized multicenter studies for national and international institutions that do not have a GMP facility. In this context, we have recently taken part to multicenter clinical 


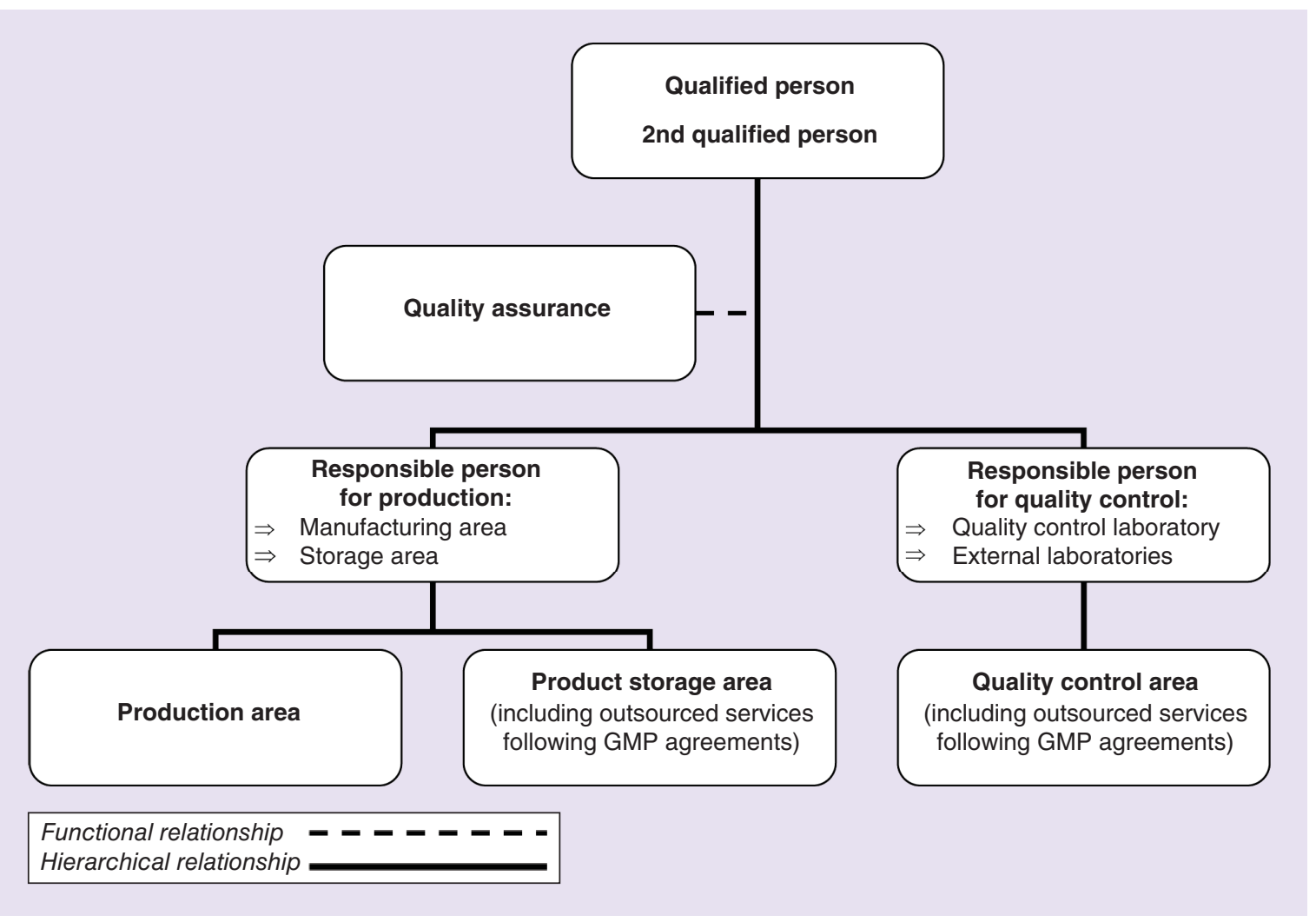

Figure 1. Organizational chart of our GMP facility.

protocols at the European level on bone regeneration (proposal acronym REBORNE), and we are just starting a new one in the orthopedic field, being the Italian GMP-manufacturing unit for six Italian clinical centers (proposal acronym ORTHOUNION).

\section{The human resources challenge}

The GMP staff and its training play a crucial role in ATMP manufacturing, where human skills and activities are still preponderant compared with automation.

All of the personnel in our organization chart have a medical, biological or biotechnological degree, come with different levels of experience, are from universities or research hospitals, and have obtained further academic qualifications (i.e., $\mathrm{PhD}$, master's degree). In this regard, the most challenging task was to transform people with a biomedical training and 'traditional' laboratory experience into pharmaceutical production and quality control specialists.

In the first phase of the team building, many efforts were made by the personnel in GMP training through a certification course and personal study. In this way, the GMP personnel can maintain their scientific skills, which are fundamental for the translational phases in the cell-based production from research to clinical application, with a curriculum enriched by the knowledge of the rules of pharmaceutical standards required for working in a GMP cell manufacturing. Figure 1 shows the organizational chart of our staff.

\section{Why are public \& private actors both important in ATMP development?}

Public and private GMP facilities are both involved in the development of advanced therapies and the best results in searching cures for still unmet clinical needs can be obtained from the synergy among them [19]. Doing preclinical and clinical research in Phase I/II trial for no-option and often rare diseases with a small number of patients is consistent with the prevalent mission of public hospitals, and this deserves the diligent allocation of public economic resources in a competitive manner to promote excellence. On the other hand, the public institutions have difficulty in moving toward late-phase studies and marketing authorization, because they are too demanding and expensive in 
Table 2. Pros and cons of autologous and allogeneic approaches in cell therapy (see text for explanation).

\begin{tabular}{|c|c|c|}
\hline Autologous transplantation & Items & Allogeneic transplantation \\
\hline Personalized therapy & Setting & 'Off-the-shelf' therapy \\
\hline Long & Time to treatment & Short \\
\hline $\begin{array}{l}\text { Unique; quality and yield may be affected } \\
\text { (e.g., systemic diseases) }\end{array}$ & Starting material & Possibility to select the best suited for the purpose \\
\hline Unpredictable & Retreatment & Possible, in short time \\
\hline Low risk & Safety & Additional risks (e.g., immunoreaction) \\
\hline Not reusable for other subjects & Unused products & Not present \\
\hline Generally low & Standardization & High \\
\hline $\begin{array}{l}\text { Both small- and large-scale production (depending on } \\
\text { the disease); single therapeutic target }\end{array}$ & Business model & $\begin{array}{l}\text { Large-scale production-potentially multiple therapeutic } \\
\text { targets }\end{array}$ \\
\hline
\end{tabular}

terms of infrastructure, personnel and marketing. At the same time, the pharmaceutical industry has generally been reluctant to invest money in such a risky business with insufficient inputs to define an informative target product profile. Indeed, despite the rapid advances in stem cell research, the scientific knowledge about these cell-based therapies is still at a very preliminary stage, and additional research is necessary to understand the biological features and the mechanisms of action of different cell types, depending on the source from which they are derived and the pathologies in which they can exert their beneficial effects. From this perspective, decisions on developing a specific ATMP can be improved by knowing the results of preclinical studies as well as the information from well-designed and Phase I and II clinical studies. This reduces the uncertainty as to the therapeutic and marketing effects and the cost/benefit profile of the candidate product.

While few big pharmaceutical companies have dared to invest money in a long-term risky project involving ATMP [20], public institutions are devoted to health research; therefore, public resources should be competitively available to them. Recently, public GMP organizations associated with small/medium enterprises (SME) and big industry can participate to specific calls to compete for funds on the European and national levels more than SME and industry alone [21]. This facilitates the conduct of early clinical studies by public institutions without the same financial risks as the pharmaceutical industry and provides a safe path to the first and most risky phase toward ATMP marketing.

In addition, pivotal studies are often stimulated and encouraged by the natural clinical environment of a hospital dedicated mainly to patients' care. Indeed, in this context, a public GMP facility can better highlight real clinical needs, since it is easier for a clinician to 'knock on the door' of a nearby cell-manufacturing hospital-based center than on a for-profit entity outside the hospital setting. In this way, the public environment can give better help, and large pharmaceutical companies can determine the best clinical market.

A perfect example of how a public cell institution can be useful in the development of ATMP is the European project 'Production and characterization of endocrine cells derived from human pancreas organoids for cell-based therapy of Type I diabetes' (proposal acronym: LSFM4LIFE). Within the consortium, there are academic groups that have discovered the human pancreatic organoids, while our facility handles all of the translational aspects according to GMP rules, and an SME considers the long-term economical sustainability of the proposed therapy with a scaled-up strategy definition. This is an example of public/private synergy that can greatly benefit Type I diabetic patients [22].

In addition, we must not forget that cell therapy is done both for autologous and allogeneic use. Table 2 shows that both approaches have pros and cons. Generally speaking, it may be considered not convenient for pharmaceutical industry to develop ATMP in the autologous setting for severe systemic diseases. The starting biological material in this case may be affected by the underlying disease and may be of variable or poor quality [23,24], thus leading to failure in ATMP production. Moreover, the time needed to produce the autologous ATMP may be incompatible with the limited therapeutic window. In other words, during the time requested for manufacturing and controls, the clinical condition of the patient may worsen, thus making impossible to administer the product that cannot be used for other subjects. Despite there are several examples of autologous ATMP developed and commercialized by pharmaceutical company, the business framework seems to be too risky at least for severe systemic diseases (e.g., diabetes, neurodegenerative disorders), and more fitted with a small-scale academic production than with the business context of a big pharmaceutical company. Nevertheless, several marketing authorizations for autologous 


\begin{tabular}{|c|c|c|c|}
\hline & Task & Outcome & Risk and costs \\
\hline A & $\begin{array}{l}\text { - To make research and generate new knowledge } \\
\text { - To produce innovative scientific evidence aimed } \\
\text { to preclinical and early clinical (Phase I) studies }\end{array}$ & $\begin{array}{l}\text { - New knowledge available (e.g., impact } \\
\text { factor) }\end{array}$ & $\begin{array}{l}\text { - Long-term medical benefit envisaged } \\
\text { - Low risk and costs }\end{array}$ \\
\hline B & $\begin{array}{l}\text { - To develop effective manufacturing process and } \\
\text { to translate the bench work into } \\
\text { pharmaceutical-grade procedures (Phases I-II) } \\
\text { - To develop technologies and to transfer them to } \\
\text { industry }\end{array}$ & $\begin{array}{l}\text { - To pave the way to cure still unmet } \\
\text { clinical needs } \\
\text { - Limited economic income (enough for } \\
\text { sustainability?) }\end{array}$ & $\begin{array}{l}\text { - Still uncertain medical benefits } \\
\text { - High costs and shared risks: } \\
\checkmark \text { Partnership with industry } \\
\checkmark \text { Support from patient organizations }\end{array}$ \\
\hline C & $\begin{array}{l}\text { - To spin-off/spin-out: chance to locate the } \\
\text { activity outside the original organization } \\
\text { - To scale up, to define standardization and } \\
\text { cost-effectiveness }\end{array}$ & $\begin{array}{l}\text { - To make advanced therapies available to } \\
\text { the majority of patients } \\
\text { - High economic income from marketing } \\
\text { authorization only if economically } \\
\text { interesting for a company }\end{array}$ & $\begin{array}{l}\text { - Potentially significant medical benefits } \\
\text { - High costs and high risks }\end{array}$ \\
\hline
\end{tabular}

ATMP have been obtained by industry [25]. They are used in diseases with high incidence (e.g., osteoarthritis) and are developed starting from the healthy part of the tissue. Therefore, also autologous ATMP specific for the treatment of disorders affecting only defined organs or sites may be suited for large-scale industrial production. Again, these are simplified considerations in a jeopardized and rapidly evolving field. We can conclude that both academia and industry are fundamental actors in the ATMP arena, and they should be seen as complementary and not as competitors.

\section{The business plan for successful ATMP development from the perspective of an academic institution}

Academia has been crucial for the development of ATMP in Europe and specifically in our country. Very often, the translation of preclinical academic research into GMP procedures has been facilitated from being conducted in blood, cell and/or tissue banks due to the availability of abundant source materials and to the familiarity with cell and tissue clinical-grade manipulation procedures, thus easily filling the gap 'from the bench to the bedside' [26]. Nevertheless, the economic effect of building and maintaining a GMP facility is significant even when ATMPs are manufactured inside a public hospital. The challenge for a public GMP facility is to project an appropriate plan to define the business strategy and positioning in the future [27]. To this aim, the development strategy will be clearly designed from the beginning with the final goal to correctly understand the efforts needed and the enterprise risk created. As summarized in Table 3, one can choose to undertake several types of activities bearing correspondingly different risks. As an example and with no pretention to be exhaustive, we list below the main objectives of an academic cell-manufacturing center:

\section{A. To be an organization aimed at generating new knowledge}

This is the less risky task and it aims at producing innovative scientific evidences in specific fields of regenerative medicine. The outcome of this activity may efficiently be measured by the different publication scores (e.g., impact factor). If the decision is taken to aim at producing scientific evidences with only a long-term perspective of directly generating new treatments, it may be convenient to focus on a single or few categories of ATMP and to limit their testing to preclinical and early clinical (maximum Phase I) studies. This context requires a small plant for manufacturing with affordable costs for a public institution. In this case, the GMP facility will act as an additional, innovative tool to perform research.

\section{B. To develop a transferable manufacturing process}

At this stage, academia may aim to develop effective but not necessarily the most efficient ATMP-manufacturing processes. Nevertheless, the process will be best tailored and ready to be transferred to industry in order to make ATMP available to a larger number of patients. Therefore, at this stage, the final aim is to prove safety and efficacy of the novel therapy in one or more severe pathologic conditions. The goal at this stage is to test ATMP in Phase I and II studies and to allow their technological transfer to industry. It is crucial, at the meantime, to find a suitable industrial partner to proceed further. Regarding the economic risk, at this stage, it is still very high: the discontinuation rate of Phase I and II clinical trials with ATMP has been estimated to be in some cases even more 
than $50 \%$ [28]. This means that a large number of ATMP in this phase will not lead to any significant improvement of the therapeutic tool box to cure severe diseases, despite the big investments. Indeed, experience gained in recent years clearly shows that, without this step, there would be no industrial development of efficient cell and/or gene therapy products for severe and incurable disease [29]. For this reason, the public support to this activity through competitive grants is mandatory, since the availability of innovative drugs for unmet clinical needs depends from the correct development of this phase. At the same time, from the interaction with industrial partners, it is expected to obtain additional private resources to be reinvested in research and development of further ATMP. Also, the role of the patient organizations in supporting the transition from this phase to the next one is crucial, especially to survey the correct use of the public resources implemented for this phase and to guarantee that ATMP will be accessible to everyone who could benefit from them [30].

\section{To spin off}

In the academic environment, when there is enough confidence in the success of a specific project on ATMP development and a realistic perception of its risk, the decision to locate this activity outside the mother organization with or without temporary economic/organizational support from the original institution can be made. Marketing approval is the aim of this step, and in this case, the public entity may modify its legal status to directly put on its shoulders the task to deliver to the market its product. High risks balanced by potentially high income are envisaged.

Whatever the choice regarding business development, there should always be attention paid to rationalize the resources. Useful tools to this aim that derive from years of field experience are optimization of the manufacturing process and times, automation, application of quality-by-design approaches and a gradual implementation and revision of the quality-management strategy. This issue becomes particularly relevant when 'investigational ATMP' move toward 'for the - market ATMP' in the later stages of clinical trials. Indeed, one of the main and critical obstacles is the final costs of these products. Several facilitating strategies have been recently developed in different European and non-European countries to facilitate access to the market (such as the adaptive framework for the approval of regenerative medical products under the Pharmaceuticals, Medical Devices and Other Therapeutic Products Act in Japan, the conditional marketing authorization in Europe, and the US FDA-accelerated approval in the USA) [31-35]. However, these approaches have no yet direct effect on academic facilities that still rely on the acquisition of public and private funds on a competitive basis. Finally, the incredible and powerful role performed by the patients and their organizations in ATMP development must be specified. They not only contribute to the systematic collection of data about their conditions and give precious and unique samples to make research possible to improve the knowledge on their diseases, but they also act as fundraisers for supporting research on new advanced therapies.

Unfortunately, the unique role of public entities has not yet completely recognized at the regional, national and European levels; and the economic support to their activities is still insufficient for their sustainability. This means that the role of the hospital-based cell-manufacturing centers is in a kind of limbo between care and research, thus excluding them from any form of stable public financing policy by the national health or insurance-based reimbursement systems. In this context, network involving academic or hospital institutions, industry and national authorities as well as patients' organizations interacting in a consolidated manner could promote the effective development of ATMP.

\section{Conclusion}

Today, from the position gained after several years of field experience, we find the landscape of regenerative medicine more fascinating than ever, even from the public and academic perspective. In our opinion, these institutions represent the natural environment where ATMP can be developed and manufactured for most Phase I and II clinical trials. Even though a lot of effort has been put forth in building, financing and maintaining academic GMP facilities, marketing authorization is still limited in most of the products developed by or with the contribution of academia.

\section{Future perspective}

Moving forward, there is the urgent need of partnership and coordination between public institutions and private pharmaceutical industries to bridge the gap from clinical research toward clinical care. 
Patient organizations, public and private institutions, regulatory agencies and industry, are all encourage to participate in the cell therapy arena. They represent the different actors that should all cooperate to efficiently deliver ATMP to the patients who put great hope in them as effective tools to treat severe and/or incurable diseases. We are convinced that coordinated actions of all the forces involved in the field will be the key to success.

\section{Executive summary}

- To make an overview of the challenges faced by academic, nonindustrial entities involved in the implementation of GMP requirements and in the development of advanced therapy medicinal products (ATMP).

- To explain our position in the debate regarding the actual and future roles of public and private actors in the regenerative medicine field.

Our history \& authorization

- 10 years ago, we pioneered the field of regenerative medicine being the first hospital-based GMP facility authorized to GMP production in Italy in 2007.

- Our devotion in this field has allowed us to reach high level of excellence in cooperation with clinical groups on a national and international basis.

Dealing with GMP application to ATMP manufacturing in a hospital: specific hurdles \& possible solutions

- Summary of the basic requirements of GMP that may represent obstacles to the implementation of a cell-manufacturing unit in a hospital environment.

- Some information on how we overcame these obstacles.

How to build \& maintain a cell-manufacturing GMP plant in a public environment

- All the life stages of a GMP facility for ATMP manufacture must be in compliance with Annex 1 of current GMP guidelines. ATMP-specific guidelines are in the way to be published by EMA.

- The construction and the maintenance of a cell-manufacturing plant imply a significant financial engagement.

- It is recommended to have a realistic picture of the clinical needs before designing a GMP facility.

The human resources

- Based on our experience, the training of GMP-specialized personnel was one of the most important challenges.

Why are public \& private actors both important in ATMP development?

- Hospital-based cell-manufacturing centers have been important 'actors' to conduct Phase I and II trials in no-option and rare diseases.

- Industry can take advantages from scientific support and preclinical studies of academia and public institutions in developing a specific ATMP.

- Public/private synergy is an added value in specific calls to compete for at European and national levels.

The business plan for successful ATMP development from the perspective of an academic institution

- An overview about the main objectives of a business plan for ATMP development.

- Attention to rationalize the resources: optimization of the manufacturing process and time, automation, application of quality by design approaches.

Conclusion

- Even though public and academic institutions represent the natural environment where ATMP can be developed, marketing authorizathion is still limited in most of these products.

Future perspective

- Patient organizations, public and private institutions, regulatory agencies and industry are all encouraged to participate to efficiently deliver ATMP to patients who put great hope in them.

\section{Acknowledgements}

The authors would like to thank all the researchers working until now at our facility.

Financial \& competing interests disclosure

This work was partially supported by funds from Fondazione II Sangue, from European Union's Seventh Program (CASCADECultivated Adult Stem Cells as Alternative for Damaged tissue, project number 223236; REBORNE - Regenerating Bone defects using New biomedical Engineering approaches; project number 241879) and HORIZON 2020 (ORTHOUNION - ORTHOpedic randomized clinical trial with expanded bone-marrow mesenchymal stromal/stem cells and bioceramics versus autograft in long bone non-UNIONs, project number 733288; LSFM4LIFE- Production and characterization of endocrine cells decrived from human pancreas organoids for the cell-based therapy of Type 1 diabetes, project number 668350). Finally, several patient associations helped us in the past or are still supporting specific projects ongoing at our cell factory and besides all the authors would like to remind Fondazione La Nuova Speranza - lotta alla glomerulosclerosi focale, Associazione Italiana Parkinsoniani - Fondazione Grigioni per 
il morbo di Parkinson and Associazione genitori neonati ad alto rischio. The authors have no other relevant affiliations or financial involvement with any organization or entity with a financial interest in or financial conflict with the subject matter or materials discussed in the manuscript apart from those disclosed.

No writing assistance was utilized in the production of this manuscript.

\section{Open access}

This work is licensed under the Attribution-NonCommercial-NoDerivatives 4.0 Unported License. To view a copy of this license, visit http://creativecommons.org/licenses/by-nc-nd/4.0/

\section{References}

Papers of special note have been highlighted as: $\bullet$ of interest; $\bullet \bullet$ of considerable interest

1. The European Parliament and the Council of the European Union. Council Regulation (EC) 1394/2007 of 13 November 2007 on advanced therapy medicinal products and amending Directive 2001/83/EC and Regulation (EC) No 726/2004. OJEU L 324/121. http://ec.europa.eu/health/files/eudralex/vol-1/reg_2007_1394/reg_2007_1394_en.pdf

2. Cuende $\mathrm{N}$, Boniface $\mathrm{C}$, Bravery $\mathrm{C}$ et al. The puzzling situation of hospital exemption for advanced therapy medicinal products in Europe and stakeholders' concerns. Cytotherapy 16(12), 1597-1600 (2014).

3. Ivaskiene T, Mauricas M, Ivaska J. Hospital exemption for advanced therapy medicinal products: issue in application in the European Union member states. Curr. Stem Cell Res. Ther. 12(1), 45-51 (2017).

4. European Commission. The rules governing medicinal products in the European Union. Volume 4 - guidelines for good manufacturing practices for medicinal products for human and veterinary use. Current Edition (2017).

http://ec.europa.eu/health/documents/eudralex/vol-4/index_en.htm

5. Colombo A, Castellani M, Piccaluga E et al. Myocardial blood flow and infarct size after CD133(+) cell injection in large myocardial infarction with good recanalization and poor reperfusion: results from a randomized controlled trial. J. Cardiovasc. Med. 12(4), 239-248 (2011).

6. Castellani M, Colombo A, Giordano R et al. The role of PET with N-13-Ammonia and F-18-FDG in the assessment of myocardial perfusion and metabolism in patients with recent AMI and intracoronary stem cell injection. J. Nucl. Med. 51(12), 1908-1916 (2010).

7. Lazzari L, Giordano R, Giorgiani $\mathrm{G}$ et al. Transplantation of ex vivo expanded cord blood progenitor cells: first experience in two children affected by hemoglobinopathies. Blood 106(11), 617A-618A (2005).

8. Giordano R, Lazzari L, Giorgiani G et al. Ex vivo expansion of cord-blood derived progenitor cells for allogeneic transplantation: a Phase I-II clinical study. Bone Marrow Transplant. 37, S246-S246 (2006).

9. Andreone P, Catani L, Margini C et al. Reinfusion of highly purified CD133(+) bone marrow-derived stem/progenitor cells in patients with end-stage liver disease: a Phase I clinical trial. Dig. Liver Dis. 47(12), 1059-1066 (2015).

10. Giordano R, Canesi M, Isalberti $\mathrm{M}$ et al. Autologous mesenchymal stem cell therapy for progressive supranuclear palsy: translation into a Phase I controlled, randomized clinical study. J. Transl. Med. 12, 14 (2014).

11. Canesi M, Giordano R, Lazzari L et al. Finding a new therapeutic approach for no-option Parkinsonisms: mesenchymal stromal cells for progressive supranuclear palsy. J. Transl. Med. 14, 127 (2016).

12. Morigi M, Rota C, Montemurro T et al. Life-sparing effect of human cord blood-mesenchymal stem cells in experimental acute kidney injury. Stem Cells 28(3), 513-522 (2010).

13. European Commission. Consultation document on the development of guidelines on good manufacturing practice for advanced therapy medicinal products pursuant to Article 5 of Regulation 1394/2007 (2015).

https://ec.europa.eu/health/sites/health/files/files/advtherapies/2015_pc/publ_cons_doc_2015.pdf

14. European Commission. Consultation document on the development of guidelines on good manufacturing practice for advanced therapy medicinal products (2016). https://ec.europa.eu/health/sites/health/files/files/advtherapies/2016_06_pc/2016_06_draft_guideline.pdf

-• Proposed EMA guidelines for advanced therapy medicinal product (ATMP)-specific GMP.

15. European Medicines Agency. Committee for advanced therapies (CAT). www.ema.europa.eu/docs/en_GB/document_library/Agenda/2017/06/WC500229566.pdf

16. Montemurro T, Vigano M, Budelli S et al. How we make cell therapy in Italy. Drug Des. Devel. Ther. 9, 4825-4834 (2015).

\section{- The description of the first hospital-based GMP facility to be approved in Italy.}

17. European Commission. Summary of the responses to the targeted stakeholder consultation on the development of guidelines on good manufacturing practice for advanced therapy medicinal products pursuant to Article 5 of Regulation 1394/2007 (2016). https://ec.europa.eu/health/human-use/advanced-therapies/2016_pc_atmp_en

18. European Commission. The rules governing medicinal products in the European Union. Volume 4 - guidelines for good manufacturing practices for medicinal products for human and veterinary use. Annex 1 Manufacture of Sterile Medicinal Products (2008). http://ec.europa.eu/health/files/eudralex/vol-4/2008_11_25_gmp-an1_en.pdf 
19. Pellegrini G, Lambiase A, Macaluso $\mathrm{C}$ et al. From discovery to approval of an advanced therapy medicinal product-containing stem cells, in the EU. Regen. Med. 11(4), 407-420 (2016).

-• An example of how cell therapy can be brought to patients, thanks to private/public synergy.

20. Schimmer J, Breazzano S. Investor outlook: rising from the ashes; GSK's European approval of strimvelis for ADA-SCID. Hum. Gene Ther. Clin. Dev. 27(2), 57-61 (2016).

-• An example of how gene therapy can be efficiently delivered to patients.

21. European Commission. Community research and development information service (CORDIS). http://cordis.europa.eu/home_en.html

22. LSFM4LIFE. Production and characterization of endocrine cells derived from human pancreas organoids for cell-based therapy of Type 1 diabetes. http://lsfm4life.eu/

23. van de Vyver M. Intrinsic mesenchymal stem cell dysfunction in diabetes mellitus: implications for autologous cell therapy. Stem Cells Dev. 26(14), 1042-1053 (2017).

24. Heathman TRJ, Nienow AW, McCall MJ, Coopman K, Kara B, Hewitt CJ. The translation of cell-based therapies: clinical landscape and manufacturing challenges. Regen. Med. 10(1), 49-64 (2015).

-. An interesting overview of cell-based therapy clinical trials and an analysis of the challenges in their manufacturing.

25. European Medicines Agency. News and events. (2017). www.ema.europa.eu/ema/index.jsp?curl=pages/news_and_events/news/2017/05/news_detail_002749.jsp\&mid=WC0b01ac058004d5c1

26. Vives J, Oliver-Vila I, Pla A. Quality compliance in the shift from cell transplantation to cell therapy in non-pharma environments. Cytotherapy 17(8), 1009-1014 (2015).

27. Abou-El-Enein M, Romhild A, Kaiser D et al. Good manufacturing practices (GMP) manufacturing of advanced therapy medicinal products: a novel tailored model for optimizing performance and estimating costs. Cytotherapy 15(3), 362-383 (2013).

- Development of a model for estimating ATMP-manufacturing costs and proposals to optimize effectiveness of academic GMP facilities.

28. Hanna E, Remuzat C, Auquier P, Toumi M. Risk of discontinuation of advanced therapy medicinal products clinical trials. J. Mark. Access Health Policy 4, 322-332 (2016).

-• One of the few available objective evaluation of the outcome of clinical trials using ATMP. Special emphasis on their effectiveness evaluated as a rate of trial discontinuation.

29. Schimmer J, Breazzano S. Investor outlook: gene therapy picking up steam; at a crossroads. Hum. Gene Ther. Clin. Dev. 27(3), 87-92 (2016).

30. Bignami F, Kent AJ, di Paola ML, Meade N. Participation of patients in the development of advanced therapy medicinal products. Bundesgesundheitsblatt-Gesundheitsforschung-Gesundheitsschutz 54(7), 839-842 (2011).

31. Cyranoski D. Japan to offer fast-track approval path for stem cell therapies. Nat. Med. 19(5), 510-510 (2013).

32. Konomi K, Tobita M, Kimura K, Sato D. New Japanese initiatives on stem cell therapies. Cell Stem Cell 16(4), 350-355 (2015).

33. Konishi A, Sakushima K, Isobe S, Sato D. First approval of regenerative medical products under the PMD act in Japan. Cell Stem Cell 18(4), 434-435 (2016).

34. Sipp D. Conditional approval: Japan lowers the bar for regenerative medicine products. Cell Stem Cell 16(4), 353-356 (2015).

35. Smith JA, Brindley DA. Conditional approval pathways: the "special" case of global regenerative medicine regulation. Rejuvenation Res. 20(1), 1-3 (2017). 